\title{
Academic and Behavioral Interventions for Students with Emotional and Behavioral Disorders (EBD): A Systematic Review
}

Nai-Cheng Kuo, Loretta Aniezue, Ashley Herzberg, Stephanie Cruz, \& Olivia Rodriguez

Department of Teaching and Leading, Augusta University

2500 Walton Way, Augusta, Georgia 30904, USA

E-mail: nkuo@augusta.edu

Received: Feb. 14, 2018 Accepted: March 27, 2018 Published: May 1, 2018

doi:10.5296/jse.v8i2.12802 URL: https://doi.org/10.5296/jse.v8i2.12802

\begin{abstract}
Teachers who work with students with emotional and behavioral disorders (EBD) play a vital role in public education, but they often experience a wide range of challenges when working with this group of students. To improve the quality of instruction for students with EBD, teachers not only need to equip themselves with a repertoire of up-to-date evidence-based practices, but also know the limitations of these practices. Through a systematic review of empirical studies published in peer-reviewed journals between 2006 and early 2018, this study reviews and discusses practical teaching and research implications on serving and supporting students with EBD in public education.
\end{abstract}

Keywords: emotional and behavioral disorders (EBD), academic intervention, behavioral intervention, single-subject research designs 


\section{Introduction}

Emotional disturbance is one of the thirteen disability categories under the U.S. federal law. According to the Individuals with Disabilities Education Act (IDEA) of 2004, students with emotional disturbances exhibit one or more of the following behaviors over a long period of time and to a degree that negatively affects their educational performance: 1) "an inability to learn that cannot be explained by intellectual, sensory, or health factors," 2) "an inability to build or maintain satisfactory interpersonal relationships with peers and teachers," 3) "inappropriate types of behavior or feelings under normal circumstances," 4) "a general pervasive mood of unhappiness or depression," and 5) "a tendency to develop physical symptoms or fears associated with personal or school problems" (IDEA, 2004). Because emotional disturbance can only be observed in behavior, the terms, "emotional disturbance" and "emotional and behavioral disorders (EBD)" are often used interchangeably.

Due to the incessant behavioral challenges exhibited by these students, an increasing number of students with EBD have been referred to alternative schools inside or outside the public school system. Teachers working with this group of students face a wide range of challenges in handling problem behaviors from mild to severe degrees. To improve the quality of instruction for students who are currently served under behavior intervention plans, teachers should equip themselves with a repertoire of up-to-date and evidence-based practices. By using a qualitative research method to review recent studies on interventions for students with EBD, we draw practical implications for both teaching and research on how to serve and support this group of students better.

\section{Methods}

\subsection{Data Collection}

We focus our qualitative review on studies that have met the following three criteria. First, the studies must involve single-subject research designs and detail its intervention procedures. In this way, educators will have a better understanding of what works, for whom, and in what contexts. Second, to inform the improvement of educational systems for students with EBD, these studies must focus on students who have been identified as having EBD between age 3 and age 21. Third, with the development of educational technology and newer instructional techniques, recent studies might be more relevant to today's classrooms. Therefore, we review studies that are published in peer-reviewed journals between 2006 and early 2018.

In the first stage of data collection, we used an electronic library search engine that covered over 35 databases and 700 published journals. The keywords we typed into the search box of this search engine were: emotional and behavioral disorders (EBD), emotional disturbance, behavior disorders, challenging behavior, and behavior management. By using these keywords, it initially yielded 11,141 studies. From this set of research studies, we screened the studies that only involved participants diagnosed as having emotional and/or behavioral disorders between the ages of 3 and 21, published between 2006 and early 2018. After applying the criteria of the age, disability category, and year of publication, 454 studies were found relevant to this present study. We then reviewed the full texts of the studies, and only 26 studies involving 
single-subject research designs were selected for this qualitative review. In the second stage of data collection, we carefully examined over 20 educational journals that have a focus on students with emotional and/or behavioral disorders to ensure that no eligible study was left out. Through the review of each journal, we identified three additional studies that were not found in the first stage of data collection. This gave a total of twenty-nine studies that were selected for the present study.

\subsection{Data Analysis}

The protocol used to analyze the studies consists of three sections: participants, academic interventions, and behavioral interventions. We analyzed the participants in these studies to understand what students were served. In this way, we would know for whom these interventions worked. Then, we grouped the studies into two categories - academic and behavioral interventions for students with EBD. By comparing these studies under each category, we synthesized the studies across different themes.

\section{Results}

\subsection{Participants}

The participants in the twenty-nine studies were analyzed under three categories - gender, ethnicity, and grade. Out of the twenty-nine studies, several studies did not specify either one or two of the listed categories. The table of the categories below, indicates that under the gender category, most of the studies focused more on male students than female students. Most of the authors studied African American Students and Caucasian students than any other ethnic group. There were also more studies on elementary students than any other grade level. Table 1 shows a summary of the participants of the studies.

Table 1. A summary of the participants

\begin{tabular}{|c|c|c|c|c|c|c|c|c|c|c|c|c|c|c|}
\hline & \multirow[t]{2}{*}{ Study } & \multicolumn{3}{|c|}{ Gender } & \multicolumn{4}{|c|}{ Ethnicity } & \multicolumn{5}{|c|}{ Grade } & \multirow{2}{*}{$\begin{array}{c}\text { Single- } \\
\text { subject } \\
\text { research } \\
\text { design }\end{array}$} \\
\hline & & $\mathrm{F}$ & M & $\mathrm{N} / \mathrm{S}$ & AA & $\mathrm{C}$ & $\mathrm{H}$ & $\mathrm{N} / \mathrm{S}$ & $\begin{array}{l}\text { Pre } \\
K\end{array}$ & Elementary & Middle & High & $\mathrm{N} / \mathrm{S}$ & \\
\hline 1 & $\begin{array}{l}\text { Allen-Deboer et al. } \\
\text { (2006) }\end{array}$ & & & 4 & 3 & 1 & & & & & & 4 & & M \\
\hline 2 & Alter et al. (2011) & 1 & 2 & & 3 & & & & & 3 & & & & M \\
\hline 3 & Alter, P. (2012) & & 3 & & 1 & 2 & & & & 3 & & & & M \\
\hline 4 & $\begin{array}{l}\text { Bowman et al. } \\
(2007)\end{array}$ & 2 & 17 & & 6 & 12 & 1 & & & & & & 19 & $\mathrm{R}$ \\
\hline 5 & Daly et al. (2009) & & & 1 & 1 & & & & & 1 & & & & M \\
\hline 6 & Ennis, R.P. (2016) & 2 & 1 & & 1 & 2 & & & & 3 & & & & M \\
\hline 7 & Flower, A. (2014) & & 3 & & & & & 3 & & 3 & & & & A \\
\hline 8 & $\begin{array}{l}\text { Gadaire \& Fisher } \\
\text { (2014) }\end{array}$ & & 3 & & & & & 3 & 3 & & & & & $\mathrm{R}$ \\
\hline 9 & $\begin{array}{l}\text { Groves, E.A \& } \\
\text { Austin, J.L (2017) }\end{array}$ & & 4 & & & & & 4 & & 4 & & & & A \\
\hline
\end{tabular}




\begin{tabular}{|c|c|c|c|c|c|c|c|c|c|c|c|c|c|c|}
\hline & \multirow[t]{2}{*}{ Study } & \multicolumn{3}{|c|}{ Gender } & \multicolumn{4}{|c|}{ Ethnicity } & \multicolumn{5}{|c|}{ Grade } & \multirow{2}{*}{$\begin{array}{l}\text { Single- } \\
\text { subject } \\
\text { research } \\
\text { design }\end{array}$} \\
\hline & & $\mathrm{F}$ & M & $\mathrm{N} / \mathrm{S}$ & AA & $\mathrm{C}$ & $\mathrm{H}$ & $\mathrm{N} / \mathrm{S}$ & $\begin{array}{c}\text { Pre } \\
\mathrm{K}\end{array}$ & Elementary & Middle & High & $\mathrm{N} / \mathrm{S}$ & \\
\hline 10 & Hansen et al. (2014) & & 3 & & & 3 & & & & 3 & & & & $\mathrm{R}$ \\
\hline 11 & Hauth et al. (2013) & 1 & 7 & & & 8 & & & & & 8 & & & M \\
\hline 12 & $\begin{array}{l}\text { Haydon et al. } \\
(2012)\end{array}$ & 1 & 2 & & 1 & 2 & & & & & & 3 & & M \\
\hline 13 & $\begin{array}{l}\text { Jitendra et al. } \\
(2010)\end{array}$ & 1 & 1 & & 1 & 1 & & & & 2 & & & & M \\
\hline 14 & Kamps et al. (2006) & 1 & 1 & & 1 & 1 & & & & 2 & & & & $\mathrm{R}$ \\
\hline 15 & $\begin{array}{l}\text { Kelly, J.R \& } \\
\text { Shogren, k. A. } \\
(2014)\end{array}$ & & 4 & & 4 & & & & & & & 4 & & M \\
\hline 16 & $\begin{array}{l}\text { Kennedy et al. } \\
(2014)\end{array}$ & 1 & 7 & & 5 & 3 & & & & 8 & & & & A \\
\hline 17 & Lane et a. (2008) & 1 & 5 & & 2 & 4 & & & & 6 & & & & M \\
\hline 18 & Lane et al. (2009) & & 2 & & 1 & 1 & & & & 2 & & & & M \\
\hline 19 & Lee et al. (2012) & & 4 & & & & & 4 & & & & & 4 & $\mathrm{R}$ \\
\hline 20 & Lingo et al. (2009) & 1 & & & 1 & & & & & 1 & & & & M \\
\hline 21 & $\begin{array}{l}\text { Maag, J. W. \& } \\
\text { Anderson, J. M } \\
(2006)\end{array}$ & 1 & 5 & & & & & 6 & & 6 & & & & M \\
\hline 22 & $\begin{array}{l}\text { McKeown et al. } \\
(2015)\end{array}$ & & & 6 & & & & 6 & & & 6 & & & M \\
\hline 23 & $\begin{array}{l}\text { Peltier, C. \& } \\
\text { Vannest, K. J. } \\
(2016)\end{array}$ & & & 2 & & & & 2 & & & & & 2 & $\mathrm{R}$ \\
\hline 24 & $\begin{array}{l}\text { Rafferty, L.A. \& } \\
\text { Raimondi, S. L. } \\
(2009)\end{array}$ & 1 & 2 & & 2 & & 1 & & & 3 & & & & M \\
\hline 25 & $\begin{array}{l}\text { Rasmussen, K. \& } \\
\text { O’Neill, R. (2006) }\end{array}$ & & 3 & & & & & 3 & & 3 & & & & M \\
\hline 26 & Saddler et al. (2017) & 1 & 5 & & 6 & & & & & 6 & & & & M \\
\hline 27 & $\begin{array}{l}\text { Vostal, B. R. \& Lee, } \\
\text { D. L. (2012) }\end{array}$ & & 3 & & & 3 & & & & & 1 & 2 & & M \\
\hline 28 & $\begin{array}{l}\text { Weeden et al. } \\
(2016)\end{array}$ & 1 & 5 & & & & & 6 & & 6 & & & & $\mathrm{R}$ \\
\hline 29 & $\begin{array}{l}\text { Wright-Gallo et al. } \\
(2006)\end{array}$ & & 2 & & & & & 2 & & & 2 & & & $\mathrm{R}$ \\
\hline & Sub-total & 13 & 72 & 9 & 26 & 28 & 1 & 39 & 3 & 59 & 17 & 9 & 6 & \\
\hline & Total & & 94 & & & & & & & & 94 & & & \\
\hline
\end{tabular}

Note: N/S - Not specified, AA - African American, C - Caucasian, H - Hispanic. M - Multiple baseline designs across participants, $\mathrm{R}$ - Reversal design, and A - Alternating treatment design. 
The majority of the students with EBD selected to participate in the studies were male and elementary students. Moreover, many studies did not specify the ethnicities of the students who participated in the studies.

\subsection{Academic interventions for students with EBD}

After a systematic review of the twelve studies categorized under academic interventions, these studies were further synthesized to identify their common characteristics based on the intervention technique used. This led to two sub-categories: instructional strategies and technology-based intervention.

\subsubsection{Instructional strategies}

Students with EBD often exhibit emotional and behavioral problems that disrupt their academic learning. In order to get these students to learn their academic content while they maintain appropriate behavior, teachers often need to use different techniques. One of them is corrective reading, which consists of sequences and scripted lessons, arranged in four levels to correspond to students' decoding skills (National Center for Education Evaluation and Regional Assistance, NCEE 2017). This intervention method is used to promote reading accuracy, fluency and comprehension skills in students who struggle with reading.

Using a systematic phonic-based intervention, implemented through an adapted version of the Corrective Reading program, Allen-Deboer, Malmgren, and Glass (2006) first trained the doctoral students participants on how to use the corrective reading curriculum and other pedagogy techniques related to the curriculum. They then grouped the participating students into three levels (B1, B2 and C). Levels B1 and B2 were designed to help the students practice word attack and phonemic skills through the use of increasingly difficult phonemic sounds and vocabulary; Level $\mathrm{C}$ consisted of the practice of advanced word-attack and phonemic skills through stories and textbook reading. This intervention includes word-attack skills (sounding out words and phonemic letter sequence, ending sounds, internal vowel conversion and word reading), story reading, which incorporated the words the students learned during the word-attack phase, and a one minute reading fluency probe, which was substituted in place of workbook activities. The results indicate that a systematic reading intervention improved academic outcomes for students with EBD, particularly in the students' oral reading fluency and reading during a standardized reading assessment.

Moreover, there are studies that used self-regulated strategies with students who have EBD in various learning contexts. These studies extend the effectiveness of self-regulated strategies from students without disabilities to students with disabilities. All of the six studies indicate strong positive findings towards writing performances of students with EBD and their decreasing problem behaviors in the classroom. For instance, using topic sentence, reason, explanation, and ending (TREE) graphic organizers, picking an idea or opinion, organize and generate notes and ideas for each part of the TREE, and write and say more (POW+TREE), Hauth, Mastropieri, Scruggs, and Regan (2013) reported that students essays were much longer than pre intervention essays. These essays included more parts and the overall quality was much higher when compared to the baselines. Post intervention maintenance and 
generalization performance were also measured. After two maintenance prompts were given, the authors found that students continued to use the strategies, even though the number of words and sentences decreased slightly.

Similarly, asynchronous audio message provided by an iPad app was used by McKeown et al. (2015) to provide individualized feedback simultaneously to six 6th grade students on their story revision skills. These self-regulated strategies were used to instruct students on story revision strategies. The strategies involve teaching a series of lessons and giving simultaneous recorded audio feedback, which the students received through the iPad app. The teachers first received a professional training in the intervention and assessment procedures, which included understanding the technology app, how to teach revision using self-regulated strategies, how to give effective genre-based feedback, assess students in a standardized manner, record spontaneous declarations, and manage files and keep a teacher notebook. After a series of practice teaching lessons with a fidelity checklist and receiving feedback, students were assessed and baseline data were collected. Teachers then engaged the students in the intervention phase. At this phase, teachers provided instructions until mastery was reached by the students and the post test was conducted. The simultaneous asynchronous feedback given to the students was reported to have significantly improved their revision behavior.

Another strategy is schema-based instruction (SBI). SBI involves the provision of a framework that enables students to understand the underlying structure of a problem by identifying and classifying the problems into types. The analysis of the problem into types, exposes the appropriate solution to that problem (Peltier \& Vannest, (2016).). In Peltier and Vannest's (2016) study, they found that students with EBD often failed mathematics competency tests and performed poorly compared to students of same age, whether typical students or otherwise. After adopting schema-based instruction, the results show that students with EBD performed better in mathematics and their problem behaviors decreased significantly.

Jitendra, George, Sood, and Price's (2010) study also shows how SBI successfully helped students with EBD improve their problem solving skills in mathematics. Their study comprised of four main steps: finding the problem type, organizing the information in the problem using a graphic organizer, planning to solve the problem, and solving the problem. Two students with EBD who functioned below grade level in mathematics were provided with SBI (45 minutes, 5 days a week for over 20 school weeks) by a trained teacher. The progress monitoring data showed that both students made significant academic progress at the end of the semester and their problem behaviors also decreased.

Furthermore, Alter, Brown, and Pylem (2011) used a four-step strategy, which included students' demonstration of writing problem-solving procedures, identifying solutions to the problem, retrieving basic facts or operation chosen, and underlining the key mathematical vocabulary in the problem. They combined these steps with question prompts that enabled students to express their mathematical thinking processes, which led students to assume ownership of their learning. The ability to think through a process using the teacher implemented mathematical problem strategy gave these students the opportunity to identify their errors and fix them. Because students were taught explicitly how to identify problems, 
explore different solutions to the problems, and examine their solutions, this strategy promoted students' ownership of learning and cultivated their self-efficacy abilities.

\subsubsection{Technology-based intervention (TBI)}

Engagement, focus, and attention are key skills students with EBD often struggle with (Flower, 2014). To improve these skills, researchers are increasingly investigating the efficacy of technology in improving the academic and behavioral performances of students with EBD such as computer-assisted Instruction (CAI) and iPad applications (Flower 2014; Haydon, Hawkins, Denune, Kimener, and McCoy, 2012). Because students with EBD tend to have a lower level of tolerance, one benefit of CAI is the immediate feedback they receive, which could increase their on-task behavior. Flower (2014) observed three students with EBD as they used an iPad during independent work practice for reading and math applications. The researcher's intent was to investigate the effectiveness of using an iPad to keep these students engaged during independent practice. This iPad condition was subsequently compared to typical independent condition that used worksheets, and showed more engaging and interactive than the use of worksheets during independent practice.

The other type of technology-based intervention (TBI) is the Sound-Field Amplification (SFA). Maag and Anderson (2006) pointed out that students with EBD often utilize noncompliant behaviors as a means of escaping undesired instructional task or a means of seeking attention, and these behaviors are even exacerbated when the classroom noise level exceeds 50 decibels $(50 \mathrm{~dB})$. However, when students could hear clearly from the teacher and know what to do, their problem behaviors decreased regardless of the noise level.

Table 2 shows a summary of the 12 academic interventions for students with EBD. 
Table 2. A summary of academic interventions for students with EBD

\begin{tabular}{ll}
\hline \multicolumn{1}{c}{ Study } & \multicolumn{1}{c}{ Description } \\
\hline $\begin{array}{l}\text { Allen-Deboer et al. } \\
(2006)\end{array}$ & $\begin{array}{l}\text { A systematic phonics-based intervention on the overall improvement of students' reading fluency and } \\
\text { accuracy, including both the post-test and standardized assessment. Intervention consists of the } \\
\text { implementation of an adapted version of Corrective Reading program, which presents skills and } \\
\text { strategies in an increasing difficult manner to students. Data collection period: 43-46 sessions across } 9 \\
\text { weeks. }\end{array}$ \\
\hline Alter et al. (2011) & $\begin{array}{l}\text { A teacher-implemented mathematics problem-solving strategy helped students improve mathematics } \\
\text { problem solving accuracy and on-task behavior. The intervention included four criterion item and } \\
\text { prompt questions to get students talking about their thinking, so they could take ownership for their } \\
\text { learning. Data collection period: 20-22 sessions. }\end{array}$ \\
\hline Ennis, R.P. (2016) & $\begin{array}{l}\text { A self-regulated strategy development intervention- TWA+PLANS helped students with EBD learn to } \\
\text { summarize informational text in social studies (i.e., Think before reading, think While reading, think } \\
\text { After reading + Pick goals, List ways to meet goals, And make Notes, Sequence notes.) Data } \\
\text { collection period: } 9 \text { writing sessions across } 6 \text { lessons of 40-50 minutes }\end{array}$
\end{tabular}

Flower, A. (2014) Students' time on task was measured using two conditions, an iPad condition (eyes directed on the screen and fingers moving on the screen); and a typical worksheet condition (eyes directed at the worksheet or the pencil moving on paper) The use of iPad increased students' on-task behavior during an independent practice condition. Data collection period: 17-21 session (10-second intervals)

Hauth et al. (2013) A Self-Regulated Strategy Development- POW-TREE mnemonic (POW: Pick my idea. Organize my notes. Write and say more; TREE: Topic sentence. Reasons (three or more). Explain reasons. Ending.), improved the persuasive essay writing skills of students with EBD, on all essay measures. Data collection period: 53 sessions

Haydon et al. (2012) iPad application (iTooch MATH Grade 5-LITE, V. 2.1, Coin Math, v. 3.0, and enVisionMATH:

Understanding Fractions v. 1.1.) used while working on math fluency was preferred by students over worksheet in solving math problem and in demonstrating active engagement, which consists of writing, raising his or her hand, choral responding, reading aloud, talking to the teacher or peer about the assignment, and placing and/or scrolling finger(s) on the iPad. Data collection period: 15 sessions

Jitendra et al. (2010) The outcomes of a schema-based intervention on students' mathematics problem solving were positive. The intervention steps included: Find the problem type, organize the information in the problem using a compare diagram, plan to solve the problem, and solve the problem. Data collection period: 20 school weeks ( 225 min per week)

Lane et al. (2008) With the SRSD approach, students were explicitly taught writing strategies (see Graham and Harris, 1996 \& 2005). Students were also taught information, vocabulary, and the skills needed to use these strategies. In addition, they learned how to use self-regulation procedures, including goal setting, self-monitoring, self-reinforcement, and self-instruction, to help them improve writing. Data collection period: 16 sessions.

Maag, J. W. \& Sound-Field Amplification helped improve the speed with which students with EBD complied with Anderson, J. M (2006) task demand directions. Data collection period: Three 20 minutes sessions

McKeown et al. (2015) Asynchronous audio feedback on writing revision practices. The instructor incorporated a self-regulated strategy development (SRSD) and provided students with individualized audio feedback through an iPad app. Data collection period:18 sessions

Peltier, C. \& Vannest, A schema-based strategy instruction (STAR Strategy- Search the problem, Translate the problem, K. J. (2016) Answer the problem, and Review the problem); and the use of reinforcements improved the performance of students with EBD on solving mathematical word problems. Data collection period: Three sessions across three weeks.

Saddler et al. (2017) A summarizing strategy mnemonic (WIN) taught through a Self-Regulated Strategy development approach improved summary writing skills of students with EBD. Data collection period: four months.

\subsection{Behavioral interventions for students with EBD}

In addition to academic interventions, techniques grounded in applied behavior analysis are also found in educating children with EBD. These techniques include behavioral momentum (high-p sequence), reinforcement (verbal and visual reinforcers, token economy), differentiated reinforcement, maintenance and generalization, group contingency, preference 
assessment, and functional behavior assessment. Each intervention is described in the following.

\subsubsection{Behavioral momentum (high-probability request sequence)}

Behavioral momentum, also known as high-probability request sequence, involves manipulating antecedent events for students who have difficulty with compliance. This behavioral technique starts from a few behaviors or tasks that the student can do followed by increasing the difficulty of the tasks gradually. Basically, it is to get the student in the mood to work first prior to presenting difficult tasks. If teachers are not sure about an effective reinforcers to students, they can conduct a formal preference assessment to determine a preference hierarchy. The assessments may include multiple stimuli without replacement (MSWO) preference assessments, multiple stimulus with replacement (MSW) preference assessments, paired stimulus preference assessments, single stimulus preference assessments, and free operant observations. In Daly, Wells, Swanger-Gagne, Carr, Kunz, and Taylor's study (2009) , they used MSWO to assess students' preferred mathematics questions. Their study showed that when students chose the questions that they preferred to do, they tended to answer more questions correctly and in turn increasing their engagement in a mathematics class.

In Lee, Lylo, Vostal, and Hua's (2012) study, they found that their targeted students (ages 15-18) tended to exhibit problem behavior to escape mathematics tasks. To prevent this, they conducted preference assessments with the students. They started with mathematics questions that these students chose. They moved questions that these students preferred least or often answered incorrectly to the end of the activities. By manipulating the order of the mathematics questions, it decreased the latency to initiate responses. Furthermore, Vostal and Lee (2012) used behavioral momentum (high-probability request sequence) to help students with EBD engage in reading. When working with their targeted fifth graders, instead of starting from fifth-grade reading paragraphs, they started from third-grade paragraphs. Once these students started to read the paragraphs that they understood, this decreased the latency to read fifth-grade paragraphs. Importantly, the researchers not only manipulated the order of task difficulty but also matched the reading contents across grade levels. That is, when students were reading lower-level paragraphs, they could build background knowledge or make a connection when they were reading higher-level paragraphs.

\subsubsection{Classwide behavior intervention}

Classwide behavior intervention is used to educate a small group of students with EBD who share common needs in the same setting. In Bowman-Perrott, Greenwood, and Tapia's (2007) study, teachers created positive learning environments for students with EBD to help each other. Each student had opportunities to serve as tutors and tutees. Students learned how to give praise to peers and provide correct answers. Teachers also used positive behavior intervention and support to facilitate classwide peer tutoring activities. Results from reversal research designs $(\mathrm{ABAB})$ indicate that students' on-task behavior accuracy in responses increased during peer tutoring instruction more than during regular teacher-led instruction across classrooms. Students who received both classwide peer tutoring and self-management 
intervention had the most improvement on their accuracy in responses compared to classwide peer tutoring alone and regular teacher-led instruction.

The Good Behavior Game (GBG) is another classwide behavior intervention strategy. There are variations of GBG because the game continues to be developed and modified by different behavior experts. However, the core elements of the game usually involve straightforward classroom rules, team memberships, behavior monitoring, and positive reinforcement (American Institutes for Research, 2017). In Groves and Austin's (2017) study, they examined a game developed by a classroom teacher. There were three rules of the game: (1) request attention appropriately, (2) show successful sitting, and (3) stay on task. Two types of group contingencies, interdependent and independent group contingencies, were used to examine which one had stronger effects. During the use of interdependent contingencies, points were delivered to the entire group only if each member of the group followed the rules. During the independent contingencies, those who followed the rules could receive the points. Each student's name was shown on a scoreboard for progress monitoring. Despite the fact that students preferred the interdependent arrangement (which was more competitive and exciting), both group contingencies during the game reduced verbal disruptions, inappropriate sitting, and off-task behavior for students with EBD.

In Weeden, Wills, Kottwitz, and Kamps's study (2016). the teacher systematically taught attending skills and goal setting to six elementary students with EBD in the same classroom. In addition, the teacher awarded the students points for appropriate behavior and provided them with tailored reinforcement. The $\mathrm{ABAB}$ research design indicates that the classwide behavior intervention successfully helped all of the six students increase their on-task behavior during reading and spelling classes.

\subsubsection{Reinforcement}

Reinforcers are often used in conjunction with prompts and self-management skills when teaching new behaviors. In Alter's (2012) study, a token economy reinforcement strategy was used to examine students' on-task behavior and mathematics performance. When students achieved the expectations and completed tasks, they would receive tokens to recognize their appropriate behavior. To maximize the use of the token economy reinforcement strategy, the teacher provided text prompts (e.g., follow directions, try your best, etc.) to remind students of the classroom expectations. The study indicates that the combination of reinforcers and prompts increased students' on-task behavior and mathematics performance.

While using reinforcers is helpful, Gadaire and Fisher's (2014) study shows that the delays of students' highly-preferred reinforcers presented before task completion produced more impulsive responses than those presented after task completion. Therefore, if it is necessary to withhold a reinforcer, by placing the reinforcer in a place where students can see it but cannot reach it, this may reduce the possibility of students exhibiting impulsive behavior. If placing a reinforcer in an proximal place is not possible, teachers may use visual aids to indicate the availability of the reinforcer.

Kennedy, Jolivette, and Ramsey (2014) further examined how different types of written praise, 
teacher praise notes (TPNs) and peer praise notes (PPNs), helped decrease inappropriate behavior of students with EBD. When students showed respect, took responsibility, accepted adult directions, and/or responded appropriately (STAR), TPNs and PPNs would be presented to the students alternatively. The results indicate that written notes successfully helped students decrease inappropriate behavior, and there was minimal to no difference between the two types of written praise. That is, when a reinforcer responds to the function of a behavior (e.g., social attention), the formats/types of the reinforcer may not be important. Additionally, in Lingo, Jolivette, and Barton-Arwood's (2009). study, the teacher provided specific oral feedback to recognize the student's effort and showed student's progress on the classroom wall, on the clipboard, and in the student's folder. By doing so, it helped the student monitor his own progress. The study shows that a combination of oral and visual feedback improved the student's appropriate behavior better than providing oral feedback alone.

When it is difficult for a student to exhibit appropriate behavior, teachers can reinforce other behavior that is incompatible (e.g., sitting still instead of walking around), alternative (e.g., raising a hand instead of talking), or less wrong behavior (e.g., lower frequency of inappropriate behavior). The idea of differentiated reinforcement is to reinforce a student's better behavior than his or her original problem behavior. There are different forms of differential reinforcement, including differential reinforcement of incompatible behavior (DRI), differential reinforcement of alternative behavior (DRA), differential reinforcement of other behavior (DRO), differential reinforcement of lower rates of inappropriate behavior (DRL), and differential reinforcement of higher rates of appropriate behavior (DRH). In addition to the use of different types of reinforcement, teachers can consider manipulating reinforcement schedules to maximize the effectiveness of a reinforcer and to help students become less dependent on external reinforcers. Different schedules of reinforcement include continuous schedules of reinforcement (CRF), fixed-ratio (FR) schedules of reinforcement, fixed interval (FI) schedules of reinforcement (also known as fixed time schedules of reinforcement), variable-ratio (VR) schedules of reinforcement, and variable-interval (VI) schedules of reinforcement (Cooper, Heron, \& Heward, 2007).

Rasmussen and O'Neill's (2006) study indicates that using fixed-time schedules of reinforcement helped reduce the rate of students with EBD using verbal disruptions to gain social attention. In other words, when social attention was given on a regular basis, it helped students with EBD control their verbal disruptions maintained by social attention. The decreases of these students' verbal disruptions were maintained during initial thinning of the schedules. Furthermore, in Wright-Gallo, Higbee, Reagon, and Davey's (2006) study, they found that students with EBD often used problem behavior to escape from task demands. By teaching students how to request an escape and ask for attention as well as reinforcing alternative behavior, these students' problem behaviors decreased. The schedule of reinforcement was successfully thinned over time to a degree that teachers could implement the intervention in a classroom setting.

\subsubsection{Functional behavior assessment}

Each behavior has multiple functions. For example, some children cry to get food, some 
children cry to gain social attention, and some children cry to escape difficult tasks. Likewise, the causes of EBD vary. The factors may be biological and/or environmental. Therefore, carefully assessing the function of a student's behavior is needed to develop an effective intervention. In Hansen, Wills, Kamps, and Greenwood's (2014) study, two students exhibited problem behavior to escape difficult tasks and to gain social attention, and another misbehaved to gain social attention. When teaching students self-management skills based on the results of functional behavior assessments (not just simply using evidence-based practices), it helped students increase both social and academic performance outcomes. Moreover, the results indicate that the effectiveness of function-based intervention was larger than the effectiveness of consequences delivered by teachers. Furthermore, in Kamps, Wendland, and Culpepper's (2006) study, it illustrated that when the teacher differentiated responses based on the functions of students' behavior, students' on-task behavior improved and their disruptive behavior decreased. This was because when intervention was relevant and responsive to the function of the behavior, it increased the likelihood that students responded to the intervention. Another study conducted by Lane, Eisner, Kretzer, Bruhn, Crnobori, Funke, Lerner, and Casey (2009) also revealed that when teachers assessed the function of students' behavior systematically and responded to the behavior individually, it increased students' engagement in learning.

\subsubsection{Self-determined behavior}

Teaching students skills like setting goals, solving problems, managing behavior, and monitoring progress is important to help them become independent learners. In Kelly and Shogren's (2014) study, students with EBD were explicitly taught how to develop their own goals, implement an action plan to achieve their goals, and utilize learning strategies. In the self-determined learning model of instruction (SDLMI), it involved three instructional phases and each phase has three guiding questions: What is my goal? What is my plan? And what have I learned? Results show that all three students' on-task behavior increased and their off-task behavior decreased after receiving an explicit and systematic self-determined behavioral instruction. While teaching self-determined behavior is needed, Rafferty and Raimondi's (2009) study shows that students with EBD perform better socially and academically during math practice when they monitored their own academic performance rather than monitoring their own attention. This is because self-monitoring of academic performance helped students see how they did, so they could compare their previous performance with their current performance. While self-monitoring of attention is important, it did not explicitly tell students if they were on the right track to get a better score.

Table 3 shows a summary of the behavior interventions for students with EBD. 
Table 3. A summary of the behavior interventions for students with EBD

\begin{tabular}{ll}
\hline \multicolumn{1}{c}{ Study } & \multicolumn{1}{c}{ Description } \\
\hline Alter, P. (2012) & $\begin{array}{l}\text { A token economy reinforcement strategy and text prompts (e.g., follow directions, try you best) that } \\
\text { helped students improve mathematics performance and increased on-task behavior. }\end{array}$ \\
\hline $\begin{array}{l}\text { Bowman et al. } \\
\text { (2007) }\end{array}$ & $\begin{array}{l}\text { Students were grouped into three classrooms. In class 1 \& 2, evidence based instructional strategy Class } \\
\text { Wide Peer Tutoring (CWPT) alone was implemented, while in class 3, a combination of Class Wide Peer } \\
\text { Tutoring and Class Wide Self-Management (CWSM) was used to compare the use of CWPT alone. } \\
\text { Evidence from the 3rd class showed students improved on time spent on tasks. }\end{array}$ \\
\hline
\end{tabular}

Daly et al. (2009) The Multiple-Stimulus Without Replacement (MSWO) preference assessment, helped identify common classroom activities students with behavioral disabilities preferred as reinforces. Selected intervention activities include time playing with a Gameboy, going to the library, walking around the school, drawing on paper, playing cards with the experimenter, playing in the gym.

Gadaire \& Fisher Using high preference stimuli to promote self-control. Delays of high preference stimuli presented before (2014) task completion produced more impulsive responding than those presented after task completion.

Groves \& Austin The Good Behavior Game (GBG) helped reduce verbal disruptions, inappropriate sitting and off-task (2017) behaviors of students with EBD The intervention included a set of rules such as request attention appropriately, show successful siting, and stay on task; grouping of students into teams and a point system of reward.

Hansen et al.

The linking of a self-management procedure and Functional Behavior assessment information proved more effective in achieving on task behavior (e.g., answering/asking questions related to the assignment, reading, writing, requesting assistance in an acceptable manner, making appropriate motor responses such as hand-raising, remaining seated) than teacher delivered consequences in students with EBD.

Kamps et al. (2006)

Functional assessments-based intervention. Interventions included modeling, teacher attention (praise), points, self-management of appropriate responses, decreased task difficulty, the use of "help tickets" to request assistance, and social attention for task completion.

Kelly \& Shogren

A Self-Determined Learning Model of Instruction (SDLMI) was used to increase on-task behaviors of (2014) students with EBD. SDLMI comprised of three problem-solving instructional phases. Each phase has questions such as, 'what is my goal?', 'What is my plan', 'What have I learned?'

Kennedy et al. (2014)

Teacher Praise Notes (TPNs) and Peer Praise Notes (PPNs) was used to decrease a variety of inappropriate behaviors of students with EBD. When students showed respect, took responsibility, accepted adult directions, and/or responded appropriately, TPNs and PPNs would be presented to them alternatively.

Lane et al. (2009) Functional assessments-based intervention to enhance students' academic engaged time. This intervention included adjusting the antecedent conditions, reinforcing the replacement behavior, and extinction.

Lee et al. (2012) High preference sequence of problems (45 single-digit multiplication problems (e.g., 4 x 6) or a series of five three-digit multiplication problems (e.g., 658 x 394) helped students with EBD initiate non preferred mathematical problems.

Lingo et al. (2009) A combination of oral ("Great job on your spelling test. You spelled 70\% of the words correctly, That's an improvement of two words from last week. Keep up the good work.", and visual feedback (display of collected data on charts posted on classroom walls, affixed to clipboards, or stored in student folders.), improved the behavior of a student with EBD.

Rafferty, \& Self-Monitoring of performance proved more effective to students with EBD in social and academic

Raimondi (2009) conditions than self-monitoring of attention.

Rasmussen \& Fixed-time schedules of reinforcement reduced the rate of social attention in students with EBD.

O’Neil (2006)

Vostal, B. R. \& A behavioral Momentum (high-p sequence) increased the reading engagement behavior of students with 
Lee, D. L. (2012) EBD.

Weeden et al.

A Class-Wide Function- related Intervention Team (CW-FIT) program improved the on-task behavior of (2016) students with EBD.

Wright-Gallo et al. A differentiated reinforcement of alternative behavior decreased the disruptive behavior of students with (2006) EBD, which was maintained by escape from task demands and access to attention.

\section{Discussion and Conclusion}

The review of the existing studies indicates that most students with EBD involved in intervention studies were male students in elementary schools. Because the population in the existing intervention studies was not inclusive, the findings of the present study signal that when implementing evidence-based practices for this group of students, teachers still need to exercise caution about how students respond to these practices, especially those who are female and in middle and high schools. Furthermore, the findings of the present study reveal that many studies did not specify the ethnicities of their participants. Because cultural and linguistic differences as well as students' social-economic status may also influence how students with EBD respond to an intervention, future studies should include these factors.

In terms of interventions, in the past decade, Forness, Kavale, Blum, and Lloyd's (1997) study showed that direct and explicit academic and behavioral interventions were more effective to help students improve their learning than simply providing them with medical treatment, different placements, or diet training. The findings of the present study also show the same pattern that when interventions focused on improving the quality of instruction and behavioral techniques, students with EBD made significant progress on both academic and behavioral performance. The instructional strategies include systematic reading programs, self-regulated learning strategies, technology, and schema-based intervention. The behavioral techniques include behavioral momentum, classwide behavior intervention, reinforcement, functional behavior assessment, and self-determination. Because students' academic and behavioral performances are intertwined, the more they are engaged in learning, the fewer problem behaviors they will exhibit in the classroom. Such results were found across many recent studies.

The synthesis of the existing studies indicates that many behavioral techniques used with students with EBD are under the umbrella of applied behavior analysis (ABA). While ABA is commonly used with students who have autism, these techniques have been increasingly used with students who have EBD. Moreover, when teachers continue equipping themselves with a repertoire of up-to-date evidence-based practices for students with EBD, they should always ask: With whom did these practices work and in what contexts did they work? By doing so, they can avoid oversimplifying the effect of these practices and therefore may adjust these practices according to the different needs of students with EBD.

\section{References}

Allen-Deboer, R. A., Malmgren, K. W., \& Glass, M. E. (2006). Reading instruction for youth with emotional and behavioral disorders in a juvenile correctional facility. Behavior Disorders, 32(1), 18-28. 
Alter, P. (2012). Helping students with emotional and behavioral disorders solve mathematics word problems. Preventing School Failure, 56(1), 55-64. https://doi.org/10.1080/1045988X.2011.565283

Alter, P., Brown, E. T., \& Pylem H. (2011). A strategy-based intervention to improve math word problem-solving skills of students with emotional and behavioral disorders. Education and Treatment of Children, 34(4), 535-550. https://doi.org/10.1353/etc.2011.0028

American Institutes for Research (2017). The Good Behavior Game. Retrieved from https://www.air.org/resource/good-behavior-game-success-classroom-and-beyond

Bowman-Perrott, L. J., Greenwood, C. R., \& Tapia, Y. (2007). The efficacy of CWPT used in secondary alternative school classrooms with small teacher/pupil ratios and students with emotional and behavioral disorders. Education and Treatment of Children, 30(3), 65-87. https://doi.org/10.1353/etc.2007.0014

Cooper, J. O., Heron, T. E., \& Heward, W. L. (2007). Applied behavior analysis ( $2^{\text {nd }}$ ed). Upper Saddle River, NJ: Pearson.

Daly, E. J., Wells, N. J., Swanger-Gagne, M. S., Carr, J. E. , Kunz, G. M., \& Taylor, A. M. (2009). Evaluation of the multiple-stimulus without replacement preference assessment method using activities as stimuli. Journal of Applied Behavior Analysis, 42, 563-574. https://doi.org/10.1901/jaba.2009.42-563

Ennis, R. P. (2016). Using self-regulated strategy development to help high school students with EBD summarize informational text in social studies. Education and Treatment of Children, 39(4), 545-568. https://doi.org/10.1353/etc.2016.0024

Flower, A. (2014). The effect of iPad use during independent practice for students with challenging behavior. Journal of Behavioral Education, 23, 435-448. https://doi.org/10.1007/s10864-014-9206-8

Gadaire, D. M. \& Fisher, W. W. (2014). The effects of presenting delays before and after task completion of self-control responding in children with behavior disorders. Journal of Applied Behavior Analysis, 47, 192-197. https://doi.org/10.1002/jaba.104

Groves, E. A. \& Austin, J. L. (2017). An evaluation of interdependent and independent group contingencies during the good behavior game. Journal of Applied Behavior Analysis, 50(3), 552-566. https://doi.org/10.1002/jaba.393

Hansen, B. D., Wills, H. P. Kamps, D. M., \& Greenwood, C. R. (2014). The effects of function-based self-management interventions on student behavior. Journal of Emotional and Behavioral Disorders, 22(3), 149-159. https://doi.org/10.1177/1063426613476345

Hauth, C., Mastropieri, M. Scruggs, T. \& Regan, K. (2013). Behavioral Disorders, 38(3), 154-170.

Haydon, T., Hawkins, R. Denune, H., Kimener, L., \& McCoy, D. (2012). A comparison of iPads and worksheets on math skills of high school students with emotional disturbance. 
Behavioral Disorders, 37(4), 232-243.

Jitendra, A. K., George, M. P., Sood, S., \& Price, K. (2010). Schema-based instruction: Facilitating mathematical word problem solving for students with emotional and behavioral disorders. Preventing School Failure, 54(3), 145-151. https://doi.org/10.1080/10459880903493104

Kamps, D., Wendland, M. \& Culpepper, M. (2006). Active teacher participation in functional behavior assessment for students with emotional and behavioral disorders risks in general education classrooms. Behavioral Disorders, 31(2), 128-146.

Kelly, J. R. \& Shogren, K. A. (2014). The impact of teaching self-determination skills on the on-task and off-task behaviors of students with emotional and behavioral disorders. Journal of Emotional and Behavioral Disorders, 22(1), 27-40. https://doi.org/10.1177/1063426612470515

Kennedy, C. Jolivette, K., \& Ramsey, M. L. (2014). The effects of written teacher and peer praise notes on the inappropriate behaviors of elementary students with emotional and behavioral disorders in a residential school. Residential Treatment for Children \& Youth, 31, 17-40. https://doi.org/10.1080/0886571X.2014.878577

Lane, K. L., Eisner, S. L., Kretzer, J., Bruhn, A. L., Crnobori, M., Funke, L., Lerner, T., \& Casey, A. (2009). Outcomes of functional assessment-based interventions for students with and at risk for emotional and behavioral disorders in a job-share setting. Education and Treatment of Children, 32(4), 573-604. https://doi.org/10.1353/etc.0.0073

Lane, K. L., Harris, K. Graham, S. Weisenbach, J. Brindle, M. \& Morphy, P. (2008). The effects of self-regulated strategy development on the writing performance of second grade students with behavioral and writing difficulties. Journal of Special Education, 41, 234-253. https://doi.org/10.1177/0022466907310370

Lee, D. L., Lylo, B., Vostal, B. \& Hua, Y. (2012). The effects of high-preference problems on the completion of nonpreferred mathematics problems. Journal of Applied Behavior Analysis, 45(1), 223-228. https://doi.org/10.1901/jaba.2012.45-223

Lingo, A. S., Jolivette, K., \& Barton-Arwood, S. M. (2009). Visual and oral feedback to promote appropriate social behavior for a student with emotional and behavioral disorders. Preventing School Failure, 54(1), 24-29. https://doi.org/10.3200/PSFL.54.1.24-29

Maag, J. W. \& Anderson, J. M. (2006). Effects of sound-field amplification to increase compliance of students with emotional and behavior disorders. Behavioral Disorders, 31(4), 378-393.

McKeown, D., Kimball, K. \& Ledford, J. (2015). Effects of asynchronous audio feedback on the story revision practices of students with emotional/behavioral disorders. Education and Treatment of Children, 38(4), 541-564. https://doi.org/10.1353/etc.2015.0020

Peltier, C. \& Vannest, K. J. (2016). Schema-based strategy instruction and the mathematical problem-solving performance of two students with emotional or behavioral disorders. 
Education and Treatment of Children, 39(4), 521-544. https://doi.org/10.1353/etc.2016.0023

Rafferty, L. A. \& Raimondi S. L. (2009). Self-monitoring of attention versus self-monitoring of performance: Examining the differential effects among students with emotional disturbance engaged in independent math practice. Journal of Behavioral Education, 18, 279-299. https://doi.org/10.1007/s10864-009-9092-7

Rasmussen, K. \& O’Neill, R. (2006). The effects of fixed-time reinforcement schedules on problem behavior of children with emotional and behavioral disorders in a day-treatment classroom setting. Journal of Applied Behavior Analysis, 39(4), 453-457. https://doi.org/10.1901/jaba.2006.172-05

Saddler, B., Asaro-Saddler, K. Moeyaert, M. \& Ellis-Robinson, T. (2017). Effects of a summarizing strategy on written summaries of children with emotional and behavioral disorders. Remedial and Special Education, 38(2), 87-97. https://doi.org/10.1177/0741932516669051

Vostal, B. R. \& Lee, D. L. (2011). Behavioral momentum during a continuous reading task: An exploratory study. Journal of Behavioral Education, 20, 163-181. https://doi.org/10.1007/s10864-011-9129-6

Weeden, M. Wills, H. P., Kottwitz, E. \& Kamps, D. (2016). The effects of a class-wide behavior intervention for students with emotional and behavioral disorders. Behavioral Disorders, 42(1), 285-293. https://doi.org/10.17988/BD-14-12.1

Wright-Gallo, G. L., Higbee, T. S., Reagon, K. A., \& Davey, B. (2006). Classroom-based functional analysis and intervention for students with emotional/behavioral disorders. 